\title{
An Electromyographic Analysis of the Temporalis Muscles and Certain Facial Muscles in Thumb- and Finger-sucking Patients
}

CLAUDE BARIL and ROBERT E. MOYERS

Montreal, Canada, and Ann Arbor, Michigan

Every dentist is frequently confronted with the problem of digital sucking in children. Yet any information he can give questioning parents relies largely on opinions, observations, or argumentation, because very little scientific evidence is found in the literature.

In 1958, Cook $^{1}$ analyzed intraoral pressures involved during thumb- or finger-sucking in a selected sample of 25 children. He found that there was a relationship between the type of pressure developed and the malocclusion observed.

After such findings, one is naturally tempted to define more precisely the part played by the digital pressure and that played by the neuromuscular complex. Is the sucking habit a source of alteration in facial muscle function? If so, what muscles are mostly involved? The purpose of this study is to examine electromyographically the involvement of selected fifth and seventh cranial nerve muscles in a group of thumband finger-suckers.

\section{EXPERIMENTAL METHODS}

The subjects in the present study included 24 of the 25 subjects investigated by Cook. ${ }^{1}$ They all had, or had had in the previous six months, an active thumb- or finger-sucking habit. The age range was five years and ten months to ten years and eleven months, with a mean of eight years and six months (Table 1).

An eight-channel electroencephalograph* modified for electromyography was used (Fig. 1). Each subject was placed in a Faraday cage to minimize electrical interference. The individual calibration of amplification for the pen-writers was $6 \mathrm{~mm} / 50$ microvolts for the temporalis and buccinator muscles and $4 \mathrm{~mm} / 50$ microvolts for the orbicularis oris and mentalis muscles. Only the "all-channel amplification control" was used for varying the gain after the recording was started. This control alters the amplification simultaneously in all recording channels. It was necessary to use it to decrease the amplitude for all subjects during biting and for some of them during sucking. Compensation for such changes in gain was made at the time of the analysis. The linear response had a frequency range between 5 and 70 cycles/sec. Muscular

This paper is derived in part from a thesis submitted in partial fulfilment of the requirements for the degree of Master of Science in the Department of Orthodontics, Horace H. Rackham School of Graduate Studies, University of Michigan. The remainder was carried out under contract No. DA-49007-MD-72.1, Research and Developmental Division, Office of the Surgeon General, Department of the Army, Washington 25, D.C.

Received for publication October 22, 1959; revised by authors February 11, 1960.

* Grass model IV-A. 
responses below or above this range are not accurately recordable by the ink writer. Only the records at paper speed of $60 \mathrm{~mm} / \mathrm{sec}$ were analyzed in this study.

Electrodes.-Two types of electrodes were used: (1) monopolar surface electrodes of approximately $3 \mathrm{~mm}$. in diameter, which were held in place by means of bentonite paste and cotton pressed over the electrodes. The selected area was cleaned with alcohol and rubbed briskly with the bentonite paste, in order to produce erythema and reduce the surface resistance; (2) monopolar needle electrodes, consisting of a silver disk of approximately $8 \mathrm{~mm}$. in diameter, in the center of which a 30-gauge needle was fixed by means of insulating acrylic. The needle itself was insulated to the extreme tip and bent at $90^{\circ}$ in order to avoid a long lever arm (Fig. 2). Electrode placement was as follows:

Temporalis muscle-the middle fibers of this muscle were studied, bilaterally, and the surface electrodes were positioned as described by Moyers. ${ }^{2}$

TABLE 1

INFORMation PERTAINING TO THE SAMPLE

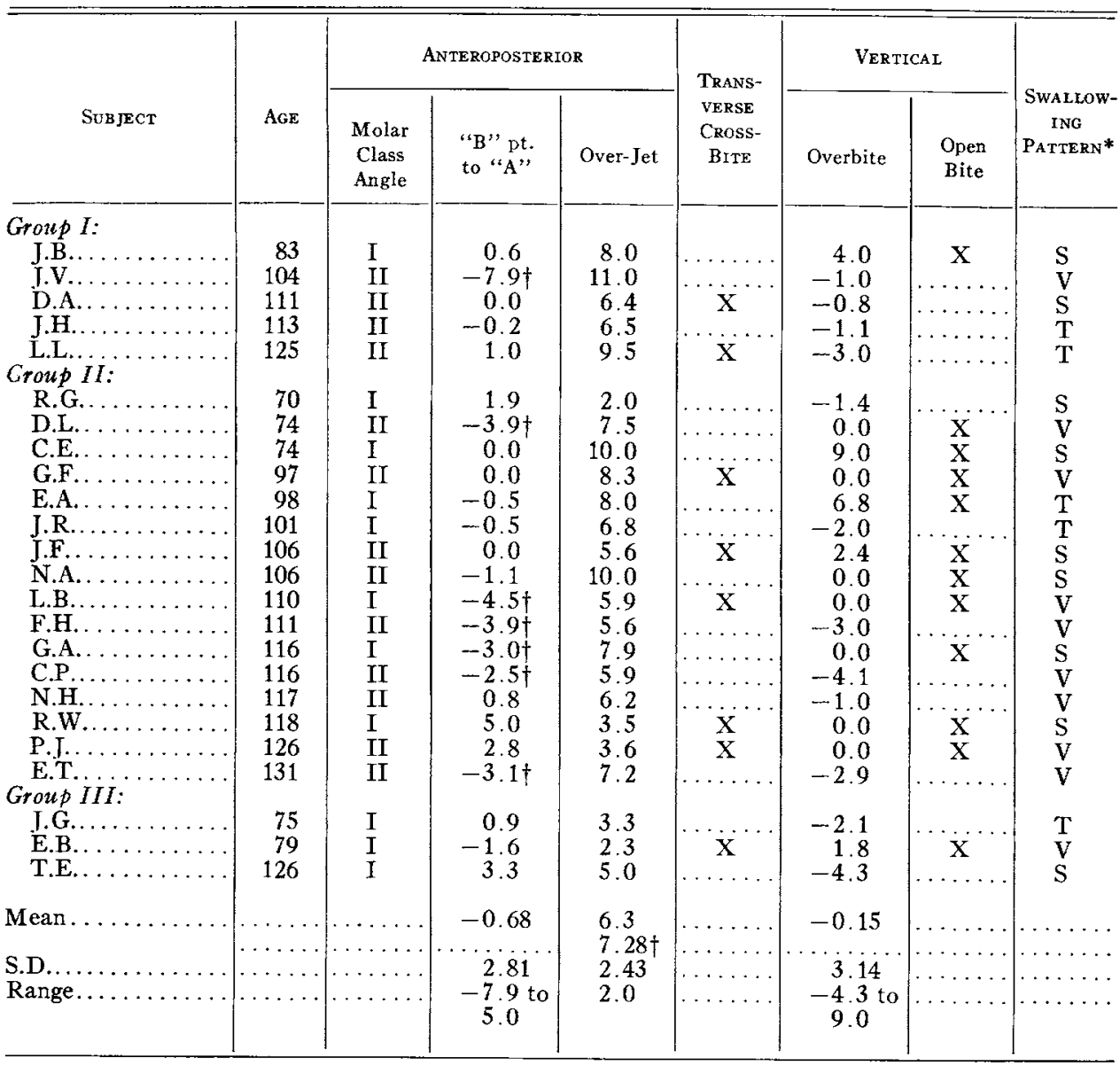

* The classification into three groups is based on evidence introduced later. $\mathrm{V}=$ visceral; $\mathrm{T}=$ transitional; and $\mathrm{S}=$ somatic swallowers.

† Skeletal Class II. 
Mentalis muscle - needle electrodes did not show any advantage over the surface electrodes; therefore, the latter were used and placed bilaterally, approximately $8 \mathrm{~mm}$. apart, over the incisive fossa.

Orbicularis oris - the upper lip was divided into six equal segments, and three surface electrodes were positioned on each side. It was possible to show that any one of the three unilateral divisions was as good as the others but that certain movements would produce asymmetry of contraction when comparing right to left. It was then decided to use the middle division, bilaterally, to study the orbicularis oris contractions (Fig. 3).

Buccinator muscle - a line joining the tragus of the ear to the commissure of the lip was explored with a probing needle electrode. A region was found, approximately half-

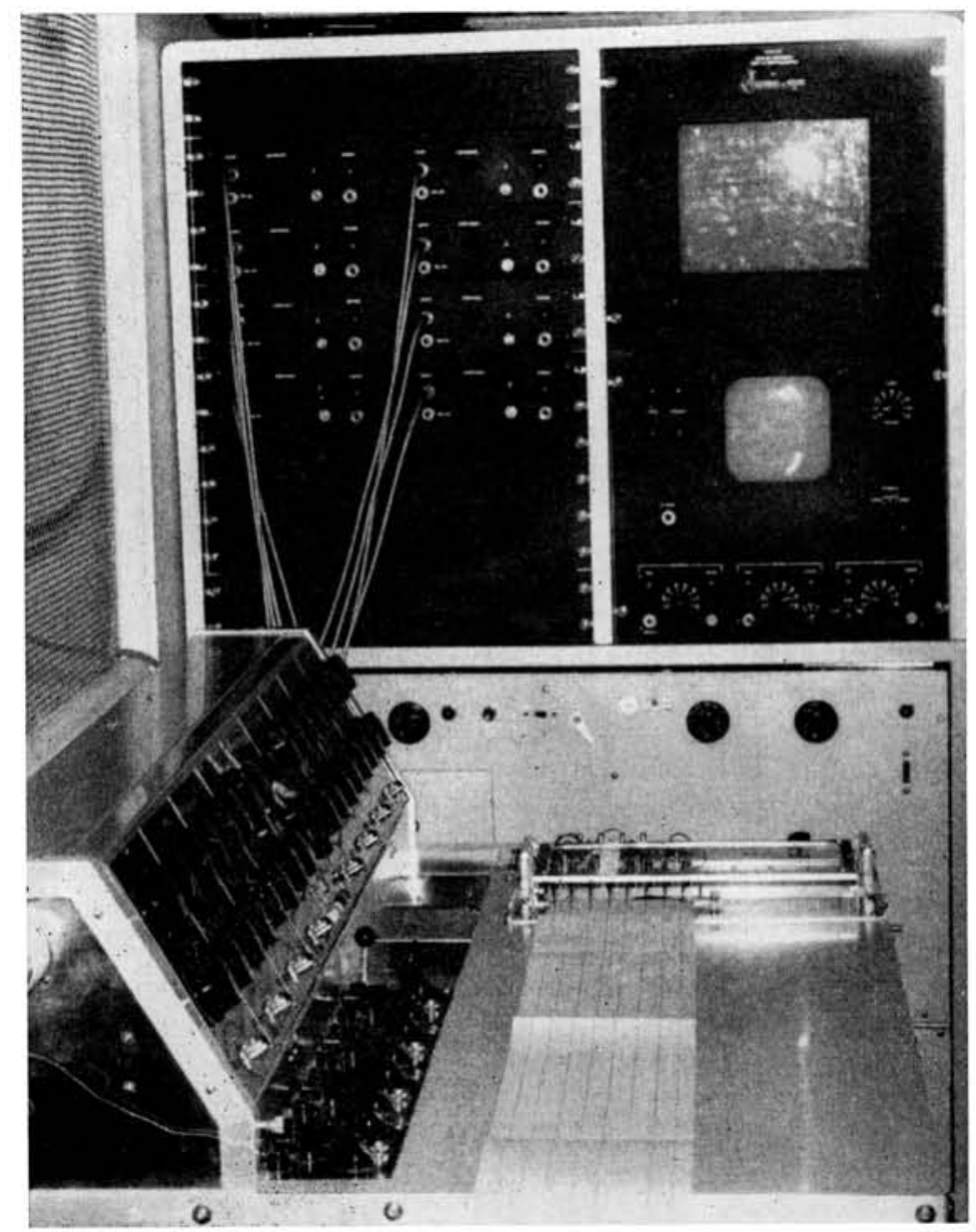

Fig. 1.-An eight-channel Grass Electroencephalograph, model IV-A, modified for electromyography. Note also the single-channel and eight-channel oscilloscopes which were used occasionally for monitoring and the window of the Faraday cage through which commands were given and the subjects were observed. 
way between the commissure of the lip and the anterior border of the masseter (determined by palpation), where the overlapping of fields, as described by Hickey, ${ }^{3,4}$ was minimal. The subject was asked to bite as hard as he could, and no contraction was registered by the needle. This was done to avoid interpreting a masseteric contraction as a buccinator one. However, it was realized that the proximity of the zygomatic, caninus, and levator labii muscles - all seventh cranial nerve muscles-was another source of overlapping fields. Therefore, this region and group of muscles will be referred to as the "buccal wall."

The ear lobe was used as reference for the temporalis muscle, while the nose was used for the mentalis, orbicularis oris, and buccal-wall muscles. At the start and end of each session, the instrument was calibrated, and an electrode resistance test was taken. For all records, the resistance was under 5,000 ohms. The room was also kept as quiet as possible to help relaxation of the patient.

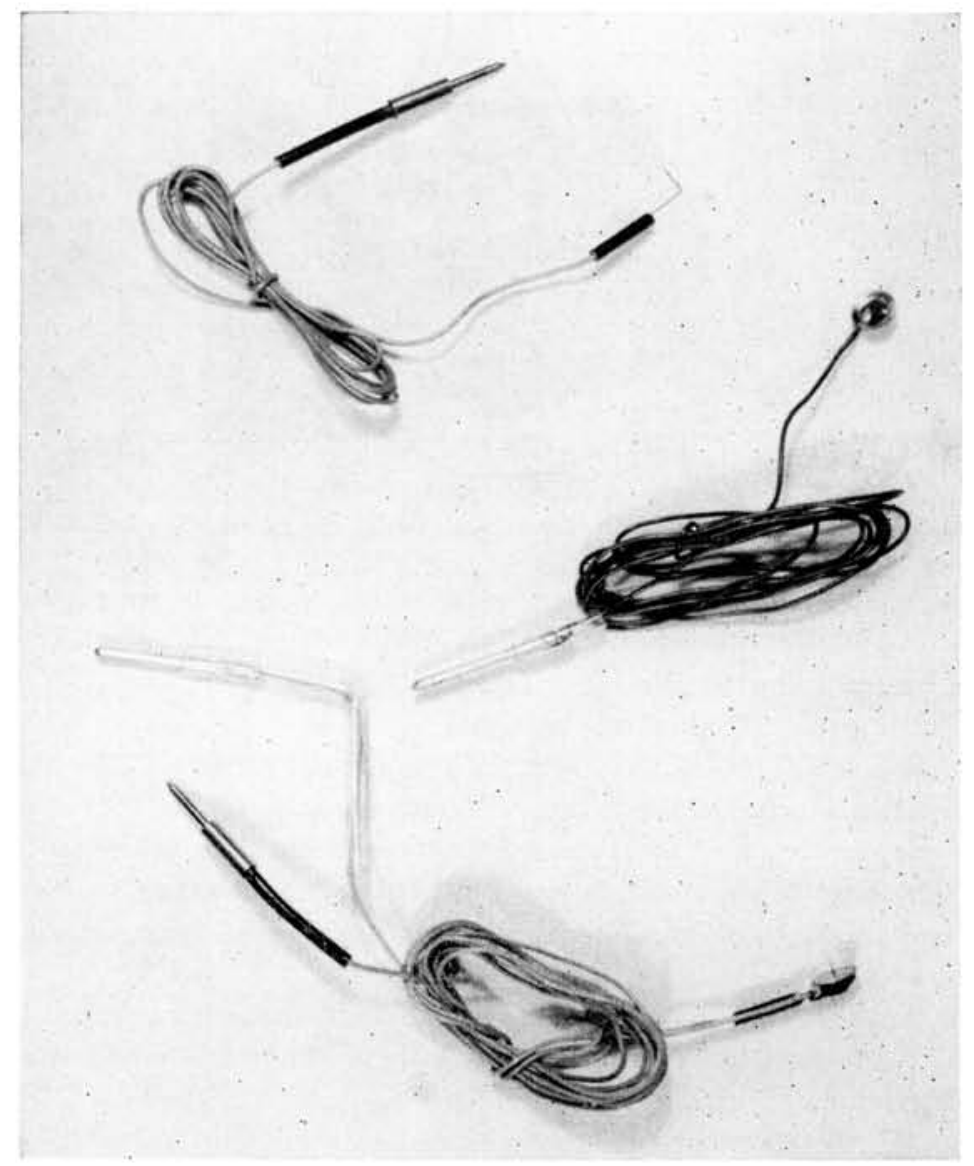

Fig. 2.-Needle and surface electrodes; needle was made by Meditron Co. and was transformed into a monopolar needle electrode as seen in the bottom. The needle was insulated by the Meditron Co. to the extreme tip. 
Movements.-Each subject was asked to do the following exercises in the order given:
1. Relax
2. Swallow
3. Tap
4. Bite hard
5. Relax
6. Swallow
7. Relax

8. Suck

9. Relax

10. Swallow

11. Tap

12. Bite hard

13. Relax

14. Swallow

Numerous repetitions of swallowing, tapping, and biting were asked. In exercise No. 8, the subject was told to suck his thumb or finger naturally, as long as it pleased him. Exercise No. 9 was done as soon as the subject removed his thumb from his mouth. Finally, at the completion of exercise No. 14, a three-minute rest period was given and exercises 8-14 were repeated.

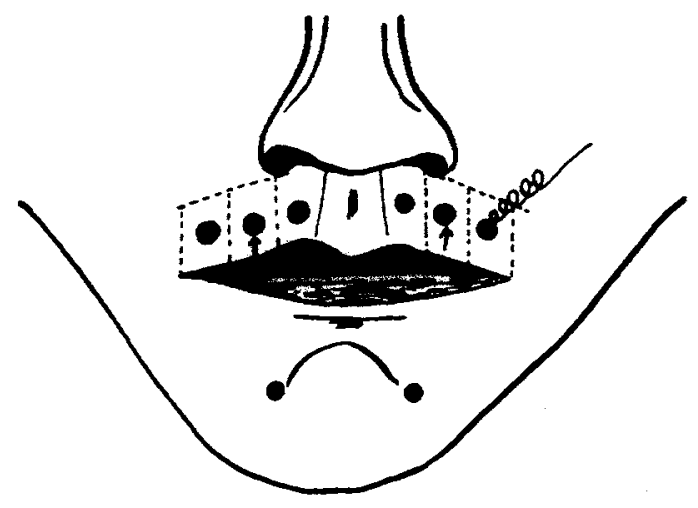

Fic. 3.-Electrode placement for the orbicular oris. The middle division was used

Cast analysis.-Alginate impressions were taken, and casts were poured for all subjects. A wax bite registering the usual occlusal position ${ }^{5}$ was also taken, and casts were trimmed according to the bite. The molar relationship, the overjet, and the transverse relation were studied on the casts.

Cephalometric analysis.-Three lateral-view cephalograms of all patients were taken, the first in the postural position without instruction, ${ }^{6}$ the second one was the usual occlusal position, and the third-5 minutes later-was taken in the postural position again. For this last one, however, the patient was asked to say " $\mathbf{M}$ " three times and to hold the position. This third cephalogram was taken on eight subjects only.

A Jenkins' analysis ${ }^{7}$ was made on each cephalogram, and, with a series of perpendiculars to "A" plane and the "natural" occlusal plane, the overbite and free-way space were also determined (Fig. $5, A$ and $B$ ).

Overbite--the distance between two perpendiculars, $i$ and $I$, to the "A" plane, tangent to the incisal edges of the most anterior lower and upper central incisors. A zero value was given to the case in which both incisal edges fell on the same plane; all positive values indicate an open bite, while a negative one indicates coverage of the lower incisors by the uppers, 
Free-way space-the distance between the perpendiculars $i$ and $i^{\prime}, i^{\prime}$ being tangent to the edge of the most anterior lower central incisor, the mandible being in postural position. The cephalograms were superposed on the nasion and the upper central incisor.

To determine the anterior or posterior trajectory of the mandible between the occlusal position and the postural position, a line tangent to the most anterior lower incisor and perpendicular to the "natural" occlusal plane was constructed. This line was traced for both the occlusal position and the postural position (Fig. $4, b$ ).
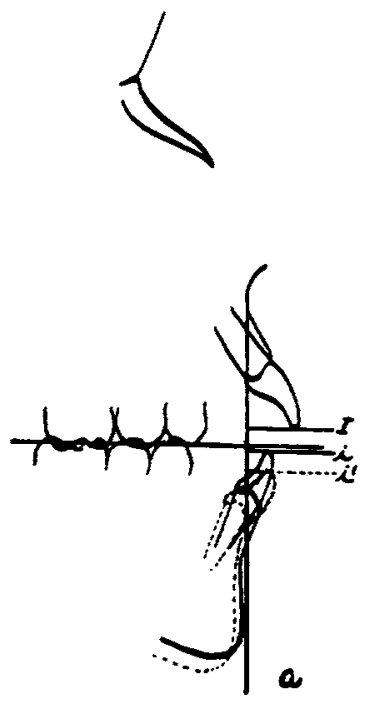
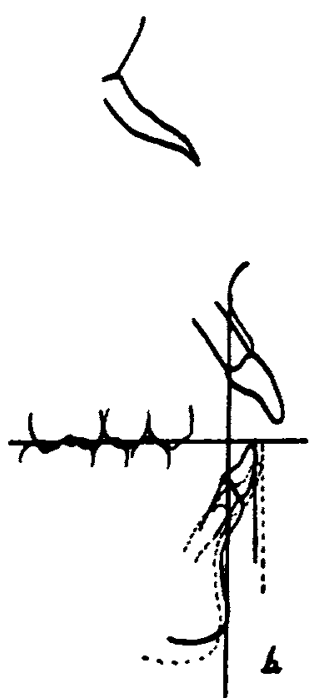

FIG. 4.- Tracings made on each cephalogram. Natural occlusal plane to "A" plane is the basis of Jenkins' analysis. Figure $4, a$, shows the tracings made for the determination of the overbite, $I$ to $i$, and of the free-way space, $i$ to $i^{\prime} ; b$ indicates how the anteroposterior evaluation was made.

\section{RESUITS}

In this study the primary concern was the sucking action and some of its possible neuromuscular effects. The first thing to consider, therefore, was the similarity or dissimilarity between the records before and after sucking. Muscular behavior in all subjects before and after sucking had a striking similarity; there was no basic difference in action potentials recorded before and after the demonstration of their habit. Superposition of the swallowing patterns recorded before sucking and after each one of the two sucking periods showed very little variation. Variations in the amplitude could be detected, but in no case were they consistent, and in all the subjects they appeared before as well as after sucking. It appears that neuromuscular activity is not altered for the short period following sucking.

Each action was then individually studied as to (1) what muscle was taking part in the given action; (2) what muscle had the greatest action potential; (3) what the timing or synchronization of the muscles was; and (4) what the over-all amplitude of the recordings was.

General findings on each action can be summed up as follows:

Postural position of the mandible.-Electromyography has shown that, unless the 
position is conditioned, the muscles are likely to be in a state of postural contraction. ${ }^{8}$ The postural potential being minimal, the pen-writers give a relatively straight line. Such recordings were found on 15 subjects, but 9 subjects showed mentalis contraction during the postural position, while all other muscles showed the typical minimal activity (Fig. 5). An attempt to eliminate such contractions was made during the recording session by asking the subject showing such activity to assume different mandibular positions. This was unsuccessful.

Swallowing.-This action was studied two ways: (1) the muscle showing the greatest amplitude during swallowing and (2) the type of swallowing.

According to the activity of the fifth or of the seventh cranial nerve muscles during swallowing, Tulley ${ }^{9}$ classified his subjects, respectively, as somatic or visceral swallowers (Fig. 6). The present selected sample followed the same general pattern as Tulley's predental students. Ten subjects were found to be visceral swallowers, 8 were purely

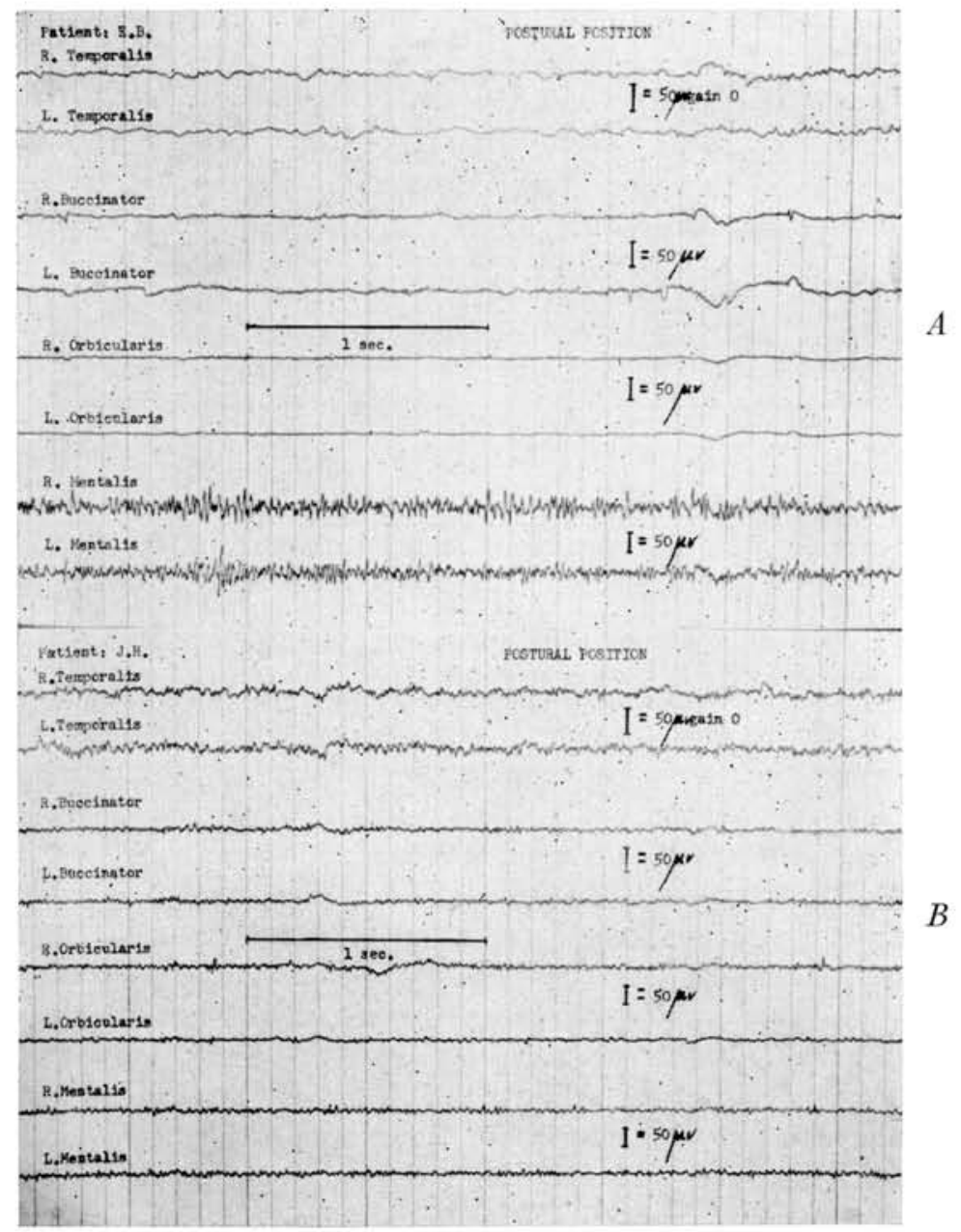

FIG. 5.-Electromyograms of two subjects in postural position. Note in $A$ the mentalis muscle as compared with normal postural position shown in $B$. The gain is identical in both records. 
somatic, while the remaining 6 were neither one nor the other exclusively. Four different patterns were found in this last group: (1) delayed contractions of the temporalis as compared to the other muscles; (2) minimal contractions of the temporalis, smaller in amplitude than the contractions of the seventh cranial nerve muscles; (3) visceral and somatic swallowing patterns equally mixed during the entire recording session; and (4) a mixture of the above three. Henceforth this latter group will be called the "transition" group in reference to Rix's "transition" period. ${ }^{10} \mathrm{He}$ labeled the period of life when the child changes from the infantile tooth-apart swallow to a so-called adult teeth-in-contact swallow as the transition period.

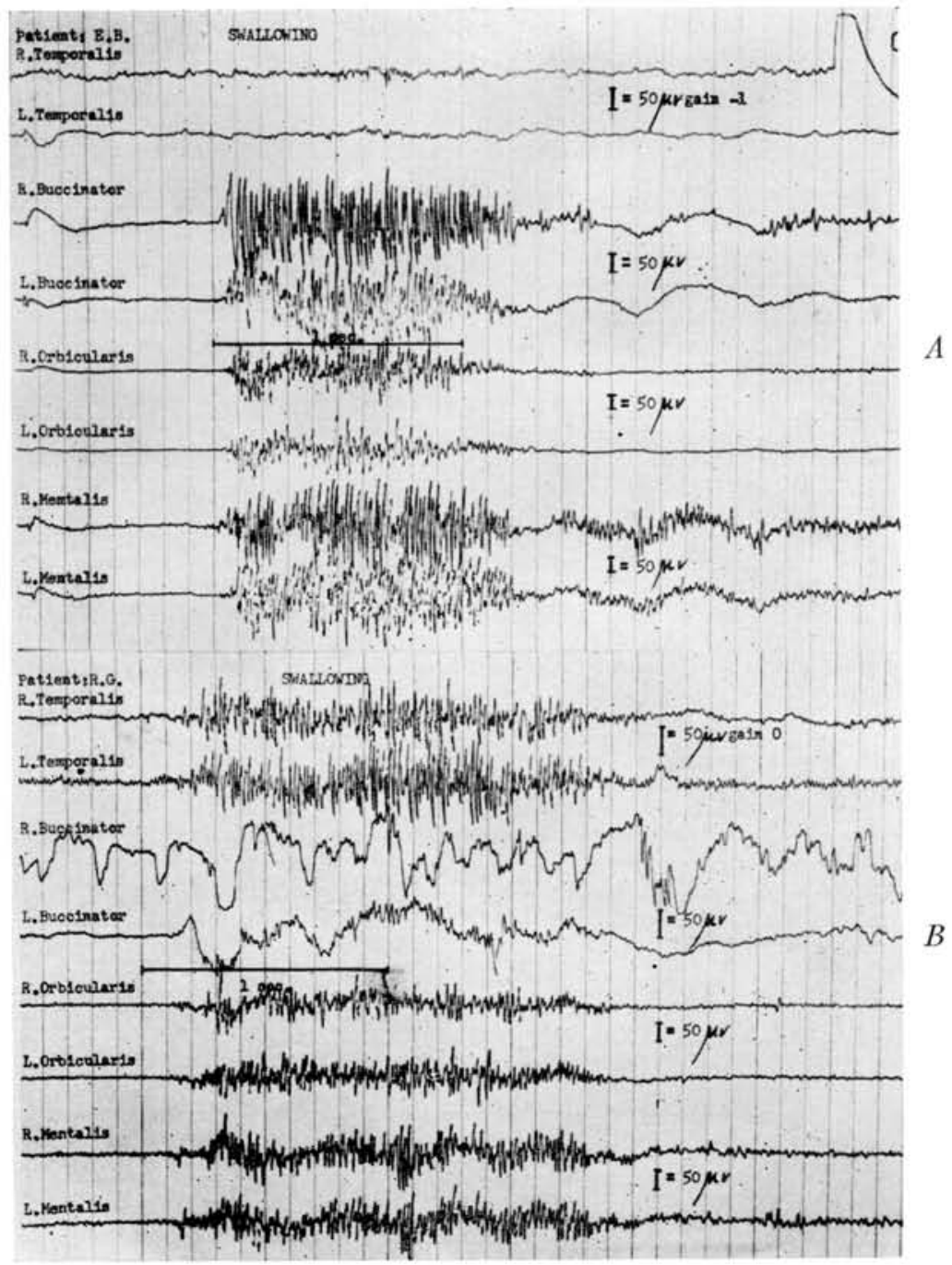

Fig. 6.-Electromyograms of two subjects during swallowing. $A$ is a visceral swallower, and $B$ is a somatic swallower. Note that the gain was decreased in $A$ because of the great amplitude of contraction of the mentalis. The minimal contraction of the temporalis muscles in $A$ is typical, and it is apparent that the seventh cranial nerve muscles are dominant during the swallowing act. 
Tapping and biting.-Both actions are primarily mediated by the fifth cranial nerve muscles. However, 19 subjects have recorded mentalis contractions during each one of these movements, while only 5 have shown contractions of the temporalis muscles alone. The 9 subjects who showed contraction of the mentalis muscles during the postural position gave a long-sustained contraction of the mentalis during tapping and biting (Fig. 7). The other 10 have produced rhythmical contractions of the mentalis synchronized with the temporalis muscles (Fig. 8). The lip showed minimal action potential during tapping and biting, and buccal-wall contractions classified as negligible were seen on the electromyograms of 4 subjects only.

Sucking.-As one would expect, the greatest display of action potential was recorded during sucking. The buccal wall, orbicularis oris, and mentalis muscles were always active, with amplitude variations between muscles and subjects (Fig. 9). No subject

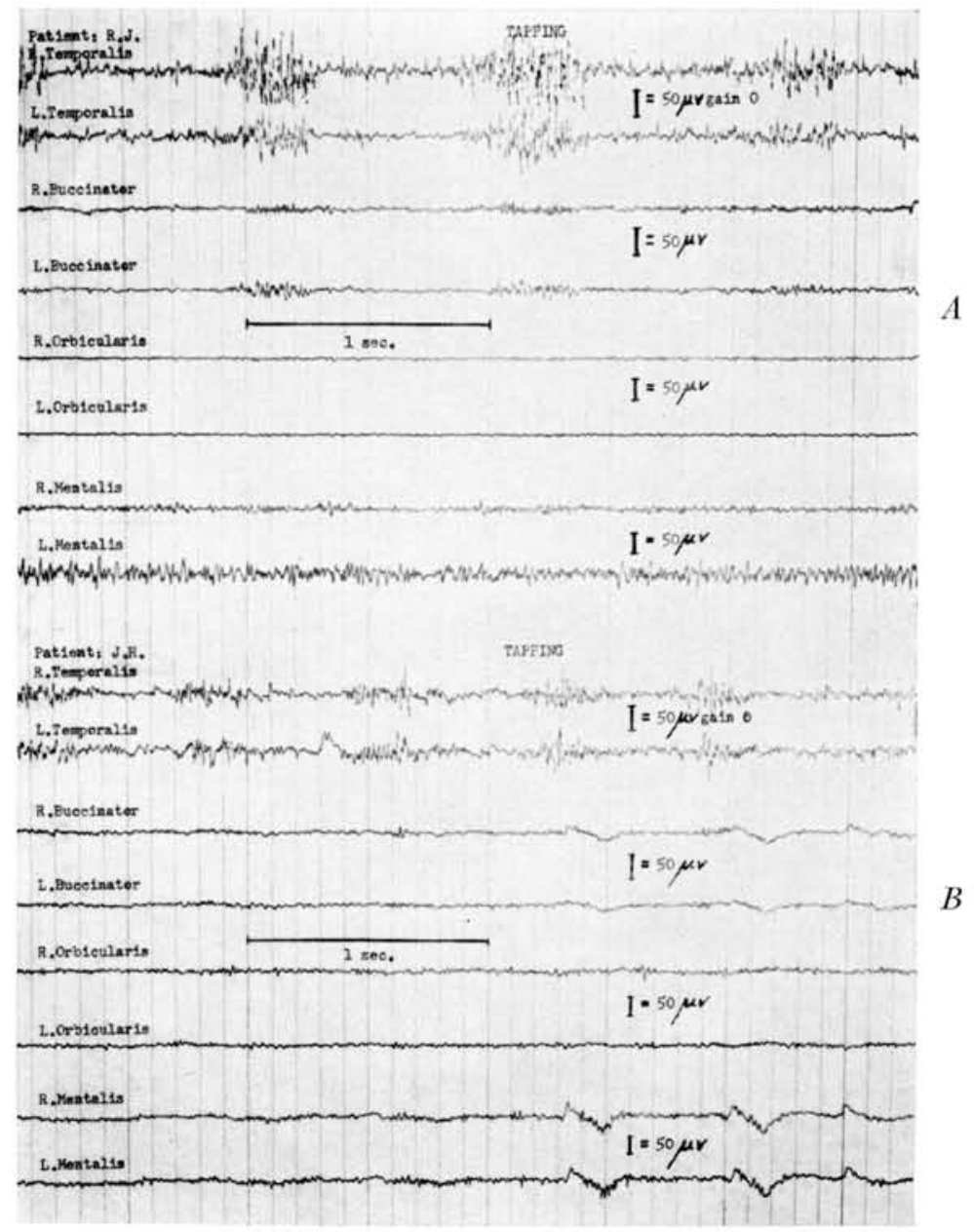

Fig. 7.-Electromyograms of two subjects during tapping. A long-sustained contraction of the mentalis muscles is seen in $A$, while $B$ is the picture of a subject showing contraction of the temporalis muscle alone during tapping. The gain is the same in both cases. 
showed any significant contraction of the temporalis muscles during sucking. These muscles showed the same behavior in sucking as they showed in postural position (Figs. 9 and 10).

It also appeared that sucking could be classified under rhythmical or sustained patterns (Fig. 10). Such a classification failed to show a correlation with any of the collected data.

The average time of sucking was 66.7 seconds for one period; the range was $14-150$ seconds. Such a wide range for a sample of 24 gives the time element a non-statistically significant value.

The contractions of the buccal wall did not, in any instance, assume the importance expected. Though never present in tapping, biting, and the postural position, the contractions of the buccal wall appeared constantly in measurable amplitude in swallowing and sucking. However, they did not appear to be the most important contrac-

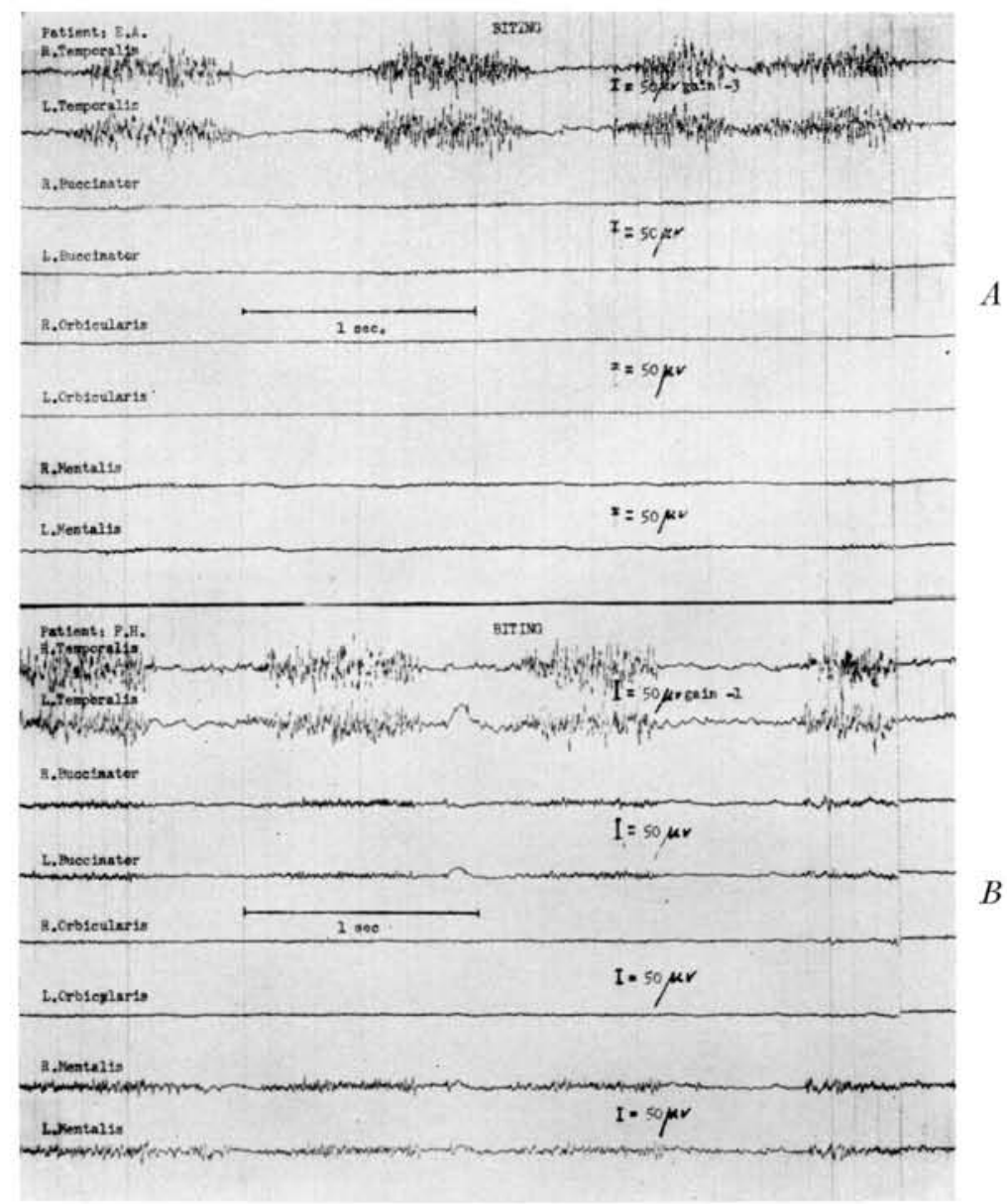

FIG. 8.-Electromyograms of two subjects during biting. $A$ shows contractions of the temporalis muscles alone, while $B$ shows rhythmical contractions of the mentalis muscles along with the temporalis muscles. Gain in record $A$ was only two-thirds of record $B$, but the relative sensitivity between each muscle is the same. 
tions in swallowing and sucking. The persistent strength of the mentalis muscles presented a surprising contrast to the weakness of the muscles of the buccal wall.

After tabulating the different actions according to the muscle activity, it was found that the general neuromuscular behavior of 21 of the 24 subjects was very similar. Five subjects (classified as Group I in Table 1) showed expected postural, tapping, and biting records; however, during swallowing and sucking, these subjects showed greater contractions in the orbicularis oris muscles than in the mentalis muscles. Sixteen subjects (classified as Group II) showed dominance of the mentalis muscles during swallowing and sucking. These 16 also had action potentials manifested in the mentalis during tapping and biting, and 8 of them even had mentalis contractions in postural position (those who could not relax that muscle when their mandible was at rest). The other 3 subjects (Group III) showed a mixture of mentalis and orbicularis

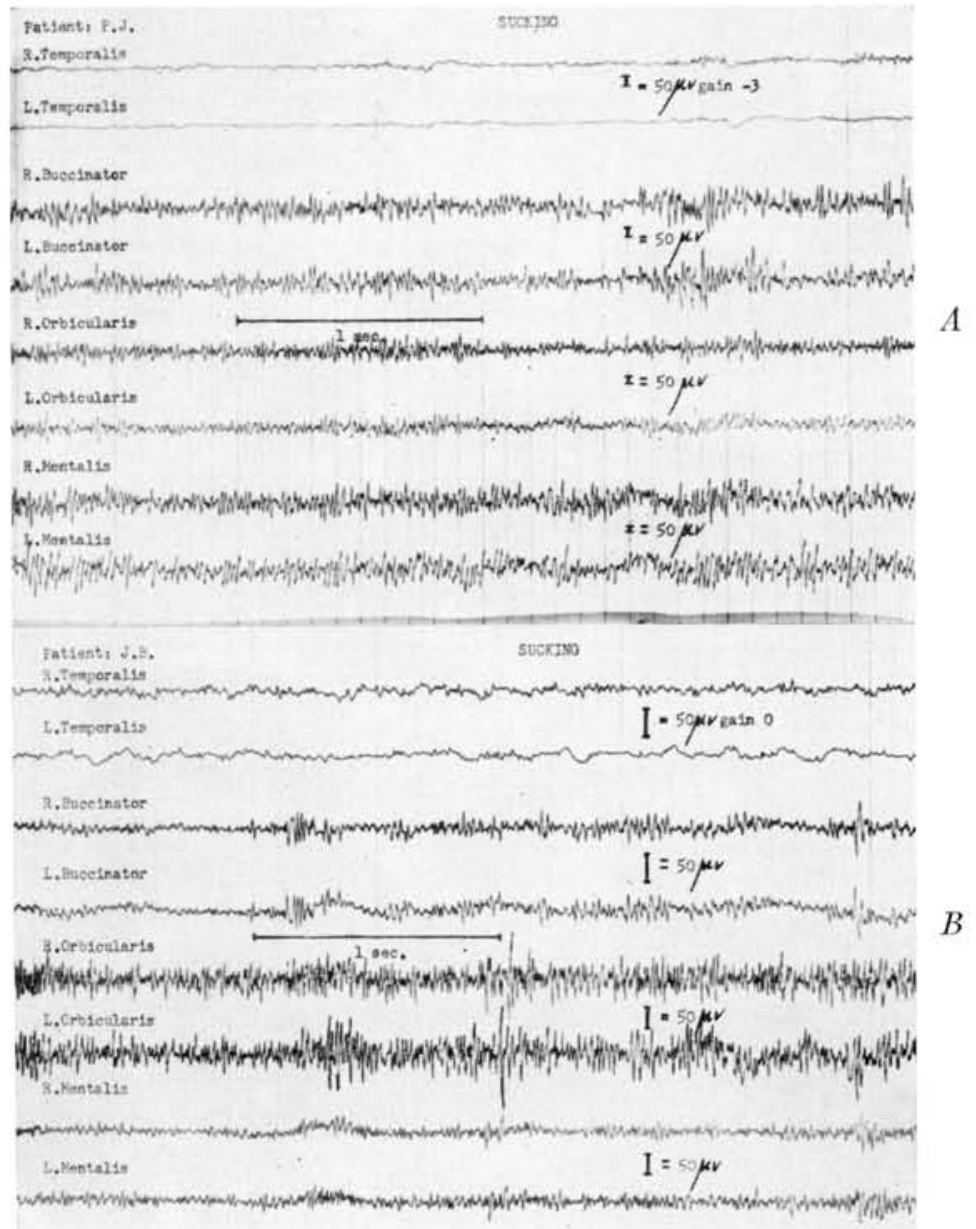

FIG. 9.-Electromyograms of two subjects during sucking. $A$ shows a sucking pattern with preponderance of the mentalis muscles. $B$ shows the dominance of the orbicularis oris muscles. Note also the minimal contraction of the temporalis muscles in both cases. 
oris dominance. These were classified in a separate group so as not to confuse the analysis of the rest of the sample.

An attempt was made to correlate all the data collected, not only with the electromyographic findings, but also with each other. There was no correlation found between these findings and Cook's study.

The over-all amplitude of contraction, the presence of cross-bite, and the finger positioning also showed a complete lack of correlation with any data.

Table 1 gives the dental and skeletal values of the sample. In the fourth column, "B" pt. to "A" plane, one finds 7 Class II's according to the Jenkins' analysis; they

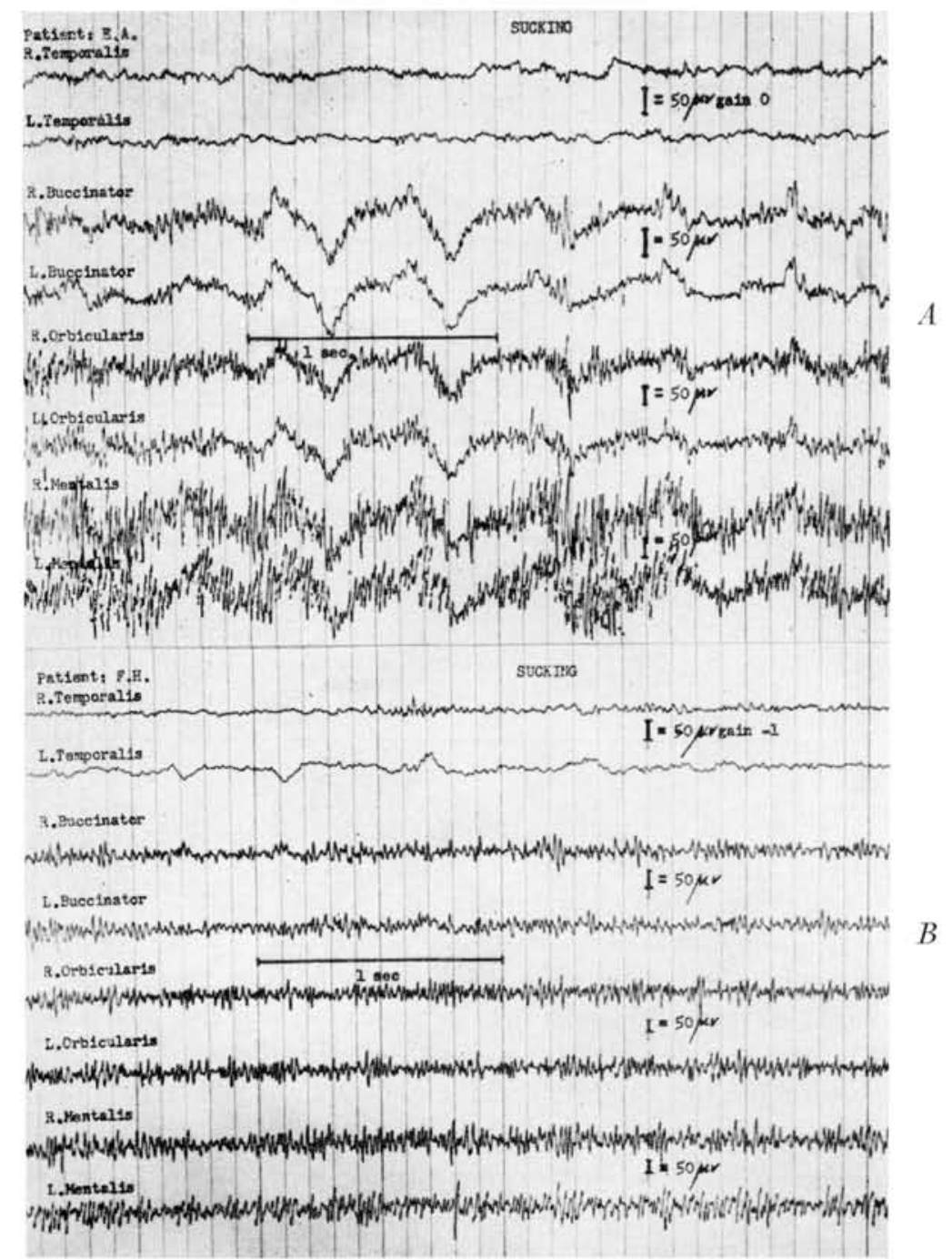

FIG. 10.-Electromyograms of two subjects during sucking. Both $A$ and $B$ show the mentalis muscles dominant. $A$ has a certain rhythm, absent from the $B$ records. Nete again the minimal contraction of the temporalis muscles. 
are indicated by an asterisk and were so classified when the given value was more than two standard deviations away from Jenkins" mean for "normal" occlusions. It is to be noted that 6 of these 7 patients are visceral swallowers. The remaining 4 visceral swallowers were skeletal Class I, three being dental Class II's and only one Class I.

A control group was studied in order to assess the validity of the numerical values collected on the sample. The control group was taken from the files of the Elementary School Growth Study, University of Michigan, and paired by age with the sample. It is shown in Table 2 that the overbite and vertical free-way space differences between the sample and the control group are not statistically significant. In fact, these values are, respectively, at the 20 and 50 per cent level of confidence. The 1 per cent level of confidence being 2.68 for the $t$-test, it is also evident that the differences in antero-

TABLE 2

Cephalometric Values of The THumb-SUCKING SAMPLE AND CONTROL GROUPS*

\begin{tabular}{|c|c|c|c|c|}
\hline & $\begin{array}{c}\text { Age } \\
\text { (Months) }\end{array}$ & Overbite & $\begin{array}{c}\text { Free-Way } \\
\text { Space/ } \\
\text { Vertical }\end{array}$ & Anteroposterior \\
\hline Mean $\left\{\begin{array}{l}\mathrm{S} \ldots \ldots \ldots \\
\mathrm{C} \ldots \ldots\end{array}\right.$ & $\begin{array}{l}102 \\
100\end{array}$ & $\begin{array}{l}-0.68 \\
-2.17\end{array}$ & $\begin{array}{l}3.58 \\
3.40\end{array}$ & $\begin{array}{l}\mathrm{P} 0.18 \\
\mathrm{P} 1.11\end{array}$ \\
\hline Range $\left\{\begin{array}{l}\mathrm{S} \ldots \ldots \ldots \\
\mathrm{C} \ldots \ldots \ldots\end{array}\right.$ & $\begin{array}{l}70-131 \\
60-132\end{array}$ & $\begin{array}{l}-4.3-9.0 \\
-7.4-1.6\end{array}$ & $\begin{array}{l}0.0-10.2 \\
1.0-8.4\end{array}$ & $\begin{array}{l}\text { P } 2.3 \text { to A } 2.4 \\
\text { P } 3.9 \text { to A } 1.5\end{array}$ \\
\hline S.D. $\left\{\begin{array}{l}\mathrm{S} \ldots \\
\mathrm{C} \ldots\end{array}\right.$ & $\cdots$ & $\begin{array}{l}3.14 \\
2.26\end{array}$ & $\begin{array}{l}2.38 \\
1.90\end{array}$ & $\begin{array}{l}1.03 \\
1.44\end{array}$ \\
\hline S.E. $\left\{\begin{array}{l}\text { S... } \\
\text { C. }\end{array}\right.$ & & $\begin{array}{l}0.654 \\
0.451\end{array}$ & $\begin{array}{l}0.496 \\
0.379\end{array}$ & $\begin{array}{l}0.214 \\
0.287\end{array}$ \\
\hline $\begin{array}{l}x^{2} \quad \mathrm{~S} . \\
t \text {-test.... }\end{array}$ & & 2.529 & $\begin{array}{l}\cdots \cdots \\
0.612\end{array}$ & $\begin{array}{l}\ldots \ldots \ldots \\
12.23\end{array}$ \\
\hline
\end{tabular}

$* \mathrm{~S}=$ sample and $\mathrm{C}=$ control.

posterior displacement of the mandible in its projection to postural position are highly significant. Indeed, this problem suggests a study in itself and is now being studied in the University of Michigan laboratories.

The free-way space could not be related to any of our data. As far as the overbite is concerned, it might be mentioned in passing that 13 cases of open bite were found in the sample, 12 of them showing a preponderance of mentalis contraction.

Seven of the 9 subjects described previously as showing hyperactivity of the mentalis muscles in postural position are among the open-bite cases. The eighth one has a very shallow bite, with $0.5 \mathrm{~mm}$. overlapping of the upper incisors, and the ninth has a normal overbite.

\section{DISCUSSION}

The significant observations in this study pertain to (1) thumb-sucking as it relates to malocclusion and (2) the neuromuscular complex of thumb-suckers as analyzed electromyographically. 
In view of the several divergent interpretations of thumb-sucking, it is not surprising that, in a small sample like the present one, numerical values are not statistically significant. If one takes the overbite values, for example, the standard deviation (S.D.) and $\chi^{2}$ tests deny any statistical significance (Table 2). If one looks at the range, however, -4.3 to 9.0 for the sample, and -7.4 to 1.6 for the control group, there is a tendency toward more positive values in the experimental sample. A range of $13 \mathrm{~mm}$. for a sample of 24 subjects does not allow statistically significant conclusions. In order to validate the apparent trend observed, a larger sample would be required, and an electromyographic analysis of such a sample would necessitate a longer period of time than was available for this study.

No electromyographic study was done on a control group. Many actions other than sucking have been studied electromyographically by different workers. These studies will serve as partial controls for the present work. In regard to sucking, three nonsucking subjects have tried unsuccessfully to register a consistent sucking pattern. The repetitious nature of a habit itself is responsible for the establishment of a neuromuscular pattern; without habit, there is no consistent pattern. To ask a non-sucking child to suck his thumb would be to propose an abnormal act. To compare one of the numerous records he might produce with records obtained from a thumb-sucking child would be most misleading. An alternative method of deriving a control group might be to teach children how to suck their thumbs, but the comparison between a highly conditioned reflex group and a non-conditioned group would hardly be valid. One feels obliged to accept this limitation and recognize it when drawing conclusions.

Electrode placement, electrode efficiency, and apparatus efficiency have been discussed by many workers. ${ }^{4,12}$ One has to decide between the high selectivity of a needle electrode and the broader perception of the surface electrode. A needle electrode was used for the buccal wall, for it is felt that the great possibility of overlapping of fields in that region necessitated its use. Tulley", 15 uses the terms "buccinator" and "buccal wall" in both his studies. His term "circumoral" appears better because of the difficulty in fractionating the seventh cranial nerve muscles electromyographically with surface electrodes.

The methodology has to be studied carefully before one compares the conclusions of two different workers. Tulley ${ }^{9,15}$ used calibration of $\frac{1}{4}$ inch for 200 or 400 microvolts. Schlossberg ${ }^{16}$ used $\frac{1}{4}$ inch for 100 microvolts. A deflection of $\frac{1}{4}$ inch $(6 \mathrm{~mm}$.) for 50 microvolts was used for the present study. This means that the present setup is eight times more sensitive than Tulley's and twice as sensitive as Schlossberg's. Perhaps this is the reason that certain activities were observed in the present study which did not appear to either Tulley or Schlossberg. The lack of findings in the buccalwall region is more surprising when one considers the higher sensitivity used in this study. This is merely the repetition of divergence already found in the literature. Alderisio $^{17}$ and Winders, ${ }^{18,19}$ studying the intraoral pressure changes involved in swallowing, came to opposite conclusions. Alderisio found an increased pressure buccally to the molar region during swallowing, while Winders found the contrary. When one considers this pressure as the expression of the contraction of the buccal-wall muscles, the present work stands, on this point, with Winders as Tulley does with Alderisio.

It was also found that the orbicularis oris muscle can and does behave as two 
separate muscles, right and left. A unilateral analysis can be accepted for a study such as this, but a precise analysis of the function of the orbicularis oris muscle would call for a bilateral analysis.

The frequent repetition of each exercise by the subjects was an assurance that a fair picture was being observed. Seven periods of 15 seconds each in the postural position, a minimum of 18 swallows, a minimum of 30 tappings and hard bites, and two periods of sucking with an average time of 66.7 seconds were each carried out for each child.

No two subjects ever gave identical records. Twenty-one subjects were remarkably consistent, and their classification is the fair image of their actual behaviors. Sometimes variation in amplitude was observed without altering the basic pattern of the contraction. Since this variation was seen both before and after sucking, it was not felt to be significant.

It was found that there is little change in the orofacial neuromuscular complex in the brief period following sucking; rather, the abnormal patterns seem so firmly established as to persist in the sucking subject. This phenomenon was found in every subject and seems to be of considerable clinical importance. The implication is that it may not be sufficient to correct the thumb-sucking habit alone if the abnormal orofacial muscular habit persists. One should then correct, or at least attempt to correct, the abnormal habitual muscular behavior in the circumoral region, as it will not disappear simultaneously with the cessation of the thumb habit. An increased contraction of the mentalis muscles is, in itself, sufficient to interfere with orthodontic treatment. Patients presenting an increased overjet with an increased mentalis contraction have a tendency for the lower lip to be pushed behind the upper incisors, preventing the reduction of the overjet or interfering in the retention.

An interesting side light to this study is the minimal contraction seen in the temporalis muscles during sucking. According to Carlsoo, ${ }^{20}$ Jarabak, ${ }^{21}$ Moyers, ${ }^{5}$ Perry, ${ }^{22}$ and others, the temporalis muscles usually show action potentials during the elevation of the mandible. As the temporalis muscles were the only fifth cranial nerve muscles studied, they were the ones used as the criteria to decide whether the subject was biting or not during sucking. It appears that no subject was biting on his thumb during sucking, as only minimal contractions were seen in the temporalis muscles. One question might be raised, though: Would the temporalis muscles show any contractions if the thickness of the thumb or the finger sucked was not forcing the mandible beyond the postural position? The hypothesis is offered that the free-way space is not responsible for the observed minimal contractions of the temporalis muscles, since it was highly variable among the subjects. Some subjects had negligible free-way space, and their thumbs were certainly forcing the mandible beyond its postural position. Even these subjects did not show other than minimal contractions of the temporalis muscles during sucking. It is questionable, therefore, whether the elevation of the mandible is responsible for the callus often seen on the sucked digit. Finally, in order to test this presumption further, three non-sucking subjects have sucked their thumbs, applying various biting pressures; action potentials in the temporalis muscles were found in every case.

It was thought that the findings of the English group on the swallowing behavior would have greater application in the present study. Rix"10 says that "poor oral habits 
behaviour" (swallowing) often lead to a sucking habit. It is impossible to draw such a conclusion from the data derived in the present study, as the sample is divided almost equally into three groups. It is impossible to designate the swallowing habits as a cause of sucking habits.

Rix, ${ }^{10}$ and Gwynne-Evans ${ }^{23,24}$ also associate visceral swallowing patterns to overjet, cross-bite, etc. Table 3 indicates why this study does not hold the same conclusions.

Too many malocclusions in this sample were not associated with visceral swallows. In fact, the mean overjet of the visceral swallowers is less than the mean of the whole sample. Four out of 8 cross-bites were visceral swallowers, and 5 out of 12 open bites were also visceral swallowers. Furthermore, similar general orofacial muscular behavior was seen in somatic swallowers as in the visceral swallowers when not swallowing. It is therefore impossible to establish a cause-to-effect relationship when 21 subjects have similar general facial muscle behavior except in the act of swallowing. The clinical implications are, however, the same; regardless of cause or effect, a muscular rehabilitation is necessary.

TABLE 3

DENTAL FIN DINGS FOR VISCERAL, SWALlOWERS

\begin{tabular}{|c|c|c|c|}
\hline $\begin{array}{c}\text { Visceral } \\
\text { Swallowers }\end{array}$ & Overjet & Cross-Bite & Overbite \\
\hline 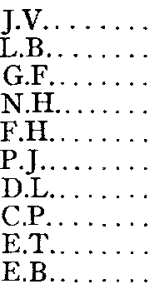 & $\begin{array}{l}11.0 \\
5.9 \\
8.3 \\
6.2 \\
5.6 \\
3.6 \\
7.5 \\
5.9 \\
7.2 \\
2.3\end{array}$ & 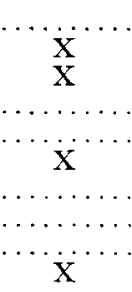 & $\begin{array}{r}-1.0 \\
0.0 \\
0.0 \\
-1.0 \\
-3.0 \\
0.0 \\
0.0 \\
-4.1 \\
-2.9 \\
+1.3\end{array}$ \\
\hline Mean. . & 5.35 & & \\
\hline
\end{tabular}

Moyers $^{2}$ and Schlossberg ${ }^{16}$ have found that in Class II subjects the mentalis muscles were more active than in Class I subjects. Both experienced difficulties in inducing relaxation of this muscle in the postural position. Their findings were probably less dramatic than the present one because they were both working with a sensitivity of 100 microvolts for $\frac{1}{4}$ inch. Of interest in the present study is the fact that we had as many Class I's as Class II's showing this abnormal mentalis pattern. It means, first, that the neuromuscular complex is not exclusively influenced by the genetic and skeletal development. Thus a child with an angle Class I malocclusion and a thumbsucking habit might precipitate Class II symptoms if this abnormal circumoral behavior appears. It would also seem that, in treatment of a Class I sucking subject, one must consider the same possible interference from the mentalis muscles as he does with Class II subjects. Finally, in considering the older subjects (T.E., R.W., G.A.O.) who remained in a Class I molar relationship in spite of a Class II's neuromuscular pattern, one must admit that the abnormal neuromuscular behavior, as well as the sucking habit, did not cause a definite malocclusion.

In concluding the discussion, the absence of a statistically significant relationship 
between open bite and the rest of the data does not alter the fact that 11 out of 12 of the open-bite cases were found on subjects showing abnormal contractions of the mentalis. An explanation is that the open bite leaves a greater space to be sealed in the acts of swallowing, whistling, etc. The mentalis muscle would help to seal the lower lip against the upper. The relative importance of lower lip and mentalis muscle is difficult to ascertain, considering the actual stage of refinement of electromyography and the fact that the lip and mentalis muscles function together so synergistically. As a result of this research, it is felt that the seventh cranial nerve muscles form a physiological functional unit that is arbitrarily divided for clinical use. Perhaps treatment directed at the mentalis muscles might effect, secondarily or even primarily, the orbicularis oris muscles. Consideration of a single circumoral muscle is almost impossible.

\section{SUMMARY}

An electromyographic study of the temporalis muscles and some of the facial muscles was performed on 24 thumb- or finger-sucking children. A radiographic and cast analysis was included. Records of intraoral pressures developed by the subjects during sucking were also available. Twenty-one subjects showed remarkable consistency in their muscular behavior. The dominant muscle was either the orbicularis oris or the mentalis. The present findings in regard to swallowing were identical with Tulley's. There is some disagreement, however, with the observations of Rix and Gwynne-Evans. The muscular behavior was found not to be altered in the short period following sucking, but rather the abnormal patterns appeared to be firmly established and to persist.

The overbite values were the numerical values showing the greatest interest, without, however, being statistically significant. Overbite seems to be related to hyperactivity of the circumoral musculature. Abnormal behavior of the mentalis previously associated with Class II division I malocclusions was, in the present study, found on any skeletal or dental malocclusion.

This study has emphasized the thought that the seventh cranial nerve muscles form a physiological functional unit and cannot easily be isolated electromyographically. It finally reflects the theory that malocclusion caused by thumb-sucking is more a matter of individual response to stimuli than a highly classified cause-and-effect syndrome.

\section{CONCLUSIONS}

1. Orofacial neuromuscular behavior is highly individualistic. One cannot assign a cause-effect relationship between the thumb habit and muscle pattern.

2. The neuromuscular behavior could not be related to the skeletal or dental aspect of the malocclusions.

3. The callus often seen on fingers of sucking subjects does not seem to be caused by mandibular elevation but by the pressure of the digit against the teeth.

4. There was no observable relationship between the retained visceral swallow and thumb-sucking.

5. There seemed to be no relationship between the pressure applied by the thumb and the neuromuscular behavior.

6. The abnormal mentalis contraction found in 19 subjects suggests that special 
early attention should be given to children displaying such contraction in conjunction with a sucking habit. The control of this muscle might be considered as preventive orthodontic therapy, and correction of the abnormal contractions persisting after orthodontic therapy would seem indicated.

\section{REFERENCES}

1. Cook, J. E. Intraoral Pressures Involved in Thumb and Finger Sucking, M.S. thesis, University of Michigan, June, 1958.

2. Moyers, R. E. T.M. Muscle Contraction Patterns in Angle Cl. II, div. I: An E.M.G. Analysis, Am. J. Orthodont., 35:837, 1949.

3. Hickex, J. C. The Influence of Overlapping Electrical Fields on the Interpretation of E.M.G., J. Pros. Den., $7: 273,1957$.

4. - E.M.G. in Dental Research. Part 1, ibid., 8:351, 1958.

5. MoYers, R. E. Some Physiologic Considerations of Centric and Other Jaw Relations, J. Pros. Den., 6:183, 1956 .

6. Werner, H. Is It Possible with Our Methods of Today To Determine the Free Way Space? Trans. Eur. Orthodont. Soc., p. 239, 1956.

7. JENKINs, D. H. Analysis of Orthodontic Deformity Employing Lateral Cephalostatic Radiography, Am. J. Orthodont., $41: 442,1955$.

8. Moyers, R. E. Some Recent E.M.G. Findings on the Orofacial Muscles, Trans. Eur. Orthodont. Soc., p. 1, 1956.

9. Tulley, W. J. Methods of Recording Patterns of Behaviour of the Orofacial Muscles Using the E.M.G., D. Record, $73: 741,1953$.

10. RIX, R. E. Some Observations on the Environment of the Incisors, D. Record, $73: 427,1953$.

11. Cuthrert, N. L., and Denslow, J. S. Electrode Efficiency and Subject Positioning in E.M.G., Proc. Soc. Exptl. Med. Biol., 58:191, 1945 article No. 14892.

12. HirschberG, G. Clinical E.M.G., Physiologic Basis, Instrumentation, Diagnostic Value, Arch. Phys, Med., $31: 576,1950$.

13. Pruzanzky, S. Application of E.M.G. to Dental Research, J.A.D.A., 44:49, 1952.

14. Schwartz, R. Instrumentation in Relation to E.M.G., Arch. Phys. Med., 30:383, 1949.

15. Tulley, W. J. Adverse Muscle Forces, Am. J. Orthodont., 42:801, 1953.

16. Schlossberg, L. An E.M.G. Investigation of the Functioning Perioral and Suprahyoid Musculature in Normal Occlusion and Malocclusion Patients, Am. J. Orthodont., 42:153, 1956.

17. Alderisio, J. P. An Electronic Technic for Recording the Myodynamic Forces of the Lip, Cheek and Tongue, J.D. Res., $32: 548,1953$.

18. Winders, R. W. Technique of Measuring Forces Exerted on Dentition, Am.J. Orthodont., 42:645, 1956.

19. - Forces Exerted on the Dentition by the Perioral and Lingual Musculature during Swallowing, Angle Orthodont., $28: 226,1958$.

20. Carlsoö, S. Nervous Coordination of Mandibular Elevators, Acta Odont. Scandinavica, Vol. 10, Suppl. 11, 1952.

21. JaRABAK, J. R. E.M.G. Analysis of Muscle Behaviour in Mandibular Movements from Rest Position, J.Pros. Den., 7:682, 1957.

22. Perry, H. T., JR. Functional E.M.G. of Temporal and Masseter in Cl. II, div. I and in Excellent Occlusion, Angle Orthodont., 25:49, 1955.

23. Gwynne-Evans, E. The Organization of Orofacial Muscles in Relation to Breathing and Feeding, Brit. D. J., 91:135 (Part 2), 1951.

24. - - - An Analysis of the Orofacial Structures with Special Reference to Muscle Behaviour and Dental Alignment, Am.J. Orthodont., 40:715, 1954. 